\title{
Evaluación de la actividad antibacteriana de extractos de microalgas usando cepas ATCC
}

\author{
JENNIFER SUASNAVAS', ", RONNY FLORES ', INÉS ECHEVERRÍA' \\ ' Facultad de Ciencias Químicas, Universidad Central del Ecuador, Quito \\ *Correspondencia: jennilu_12@hotmail.com
}

Recibido: 8 septiembre 2017. Aceptado: 15 noviembre 2017

\section{Resumen}

La presencia de bacterias multirresistentes es un problema de salud pública a nivel mundial, lo que genera la necesidad de buscar alternativas terapéuticas de preferencia de origen natural. El objetivo del trabajo de investigación fue evaluar la actividad antibacteriana de extractos etanólicos, metanólicos y hexánicos de los géneros de microalgas: Chlorella sp., Anabaena sp., Oscillatoria sp. y Stichococcus sp., recolectadas de la estación antártica ecuatoriana Pedro Vicente Maldonado. Los extractos fueron obtenidos mediante la técnica de extracción Soxhlet. La actividad antibacteriana se evaluó en primera instancia con el método de dilución en agar, con el que se identificó que de los 12 extractos evaluados, los extractos metanólicos de las microalgas Oscillatoria sp. y Stichococcus sp. presentaron actividad inhibitoria frente a la cepa bacteriana Staphylococcus aureus ATCC 25923, mientras que ningún extracto presentó actividad frente a Escherichia coli ATCC 25922. Con los extractos metanólicos de Oscillatoria sp. y Stichococcus sp. se desarrolló el método de Kirby Baver, obteniéndose halos de inhibición de mayor tamaño en el extracto de Oscillatoria sp. Al comparar la actividad de los extractos de las microalgas con los antibióticos de amplio espectro trimetoprima sulfametoxazol y ciprofloxacina, se concluye que estos productos farmacéuticos provocan mayor sensibilidad. A través de un tamizaje fitoquímico se identificaron terpenoides, fenoles y alcaloides los cuales podrían ser responsables de la actividad antibacteriana.

Palabras clave: Extractos de microalgas, método de Kirby Baver, halos de inhibición, actividad antibacteriana.

\section{Evaluation of the antibacterial activity of microalgae extracts using ATCC strains}

\section{Abstract}

The presence of multiresistant bacteria is a public health problem worldwide which generates the need to search therapeutic alternatives of natural origin. The objective of this research was to evaluate the antibacterial activity of ethanolic, methanolic and hexane extracts of microalgae gender: Chlorella sp., Anabaena sp., Oscillatoria sp. and Stichococcus sp., collected at the Ecuadorian Antarctic Station Pedro Vicente Maldonado. The extracts were obtained by the Soxhlet extraction technique. The antibacterial activity was first evaluated with the agar dilution method, and it was identified that from the 12 extracts evaluated, the methanolic extracts of the microalgae Oscillatoria sp. and Stichococcus sp. presented inhibitory activity against the bacterial strain Staphylococcus aureus ATCC 25923, whereas no extract presented activity against Escherichia coli ATCC 25922. With the methanolic extracts of Oscillatoria sp. and Stichococcus sp. the Kirby Baver method was developed, obtaining zones of inhibition that shows greater antibacterial activity by the Oscillatoria sp. extract. When comparing the activity of the microalgae extracts with the broad spectrum antibiotics trimethoprim sulfamethoxazole and ciprofloxacin, the conclusion is that these pharmaceutical products cause greater sensitivity. Through phytochemical screening terpenoids, phenols and alkaloids were identified which could be responsible for antibacterial activityl activity.

Keywords: microalgae's extracts, Kirby Baver method, zones of inhibition, antibacterial activity. 


\section{Introducción}

En los últimos años se ha evidenciado incremento de la resistencia a los antimicrobianos a nivel mundial, convirtiéndose en un problema de salud pública, ya que los microorganismos han generado una mayor cantidad de mecanismos de resistencia a los antibióticos usados de forma ordinaria [1] [2] , por lo que se ve la necesidad de encontrar componentes bioactivos de fuentes naturales. Una posibilidad son las microalgas, en este caso a partir de los 4 géneros: Anabaena sp., Oscillatoria sp., Stichococcus sp. y Chlorella $s p$. , recolectadas de la estación antártica ecuatoriana Pedro Vicente Maldonado. Los respectivos extractos se obtienen mediante la técnica Soxhlet mientras que para evaluar la actividad antibacteriana se usa en primer lugar la técnica de dilución en agar que permite evaluar cualitativamente y de forma sencilla un número moderado de condiciones (tipos de extracto frente a cepas bacterianas). Luego, con los extractos en los que se identificó una actividad inhibitoria de crecimiento bacteriano, se desarrolló la técnica de Kirby Baver, semicuantitativa que permite evidenciar el tamaño de los halos de inhibición para establecer cuál de los extractos genera una mayor actividad relativa y compararlos frente a antibióticos utilizados como control. Finalmente, es necesario realizar un tamizaje fitoquímico para identificar los posibles grupos químicos que generan la actividad antibacteriana.

Existe una elevada cantidad de estudios relacionados con la evaluación de la actividad antibacteriana a partir de sustancias bioactivas obtenidas de extractos de diversos tipos de microalgas, lo que se consigue por distintos métodos y así mismo realizando diversos ensayos de sensibilidad. El género de microalga Chlorella sp. es uno de los más estudiados, dentro de sus componentes están ácidos grasos y chlorellin, se ha aducido que alguno de estos compuestos genera actividad antibacteriana tanto sobre bacterias Gram positivas como Gram negativas. [3]

En otro estudio se usó cianobacterias incluyendo el género de Anabaena sp., que se caracterizó por ser una fuente rica en proteínas y de una gran variedad de productos químicos y farmacéuticos, evidenciando que las cepas Gram negativas fueron más resistentes a los extractos con respecto a los Gram positivas [4], sin embargo, en otro estudio se menciona que se generó mayor inhibición en cepas de bacterias Gram negativas, lo que sería dependiente de las microalgas y solventes usados en la extracción. [5]

En Ecuador también se han realizado investigaciones relacionadas con actividad antibacteriana usando mi- croalgas, como es el caso de Chlorella con la que se obtuvo extractos que generaron halos de inhibición contra la bacteria Staphylococcus aureus, lo que concuerda con uno de los estudios mencionados anteriormente sobre este género de microalga; mientras que en otra investigación donde se evaluó la actividad con los extractos de las algas Euglena viridis y Oscillatoria sp, no se obtuvo resultados favorables en Escherichia coli ni Staphylococcus aureus. [6] [7]

La importancia de este estudio radica en identificar fuentes alternativas de compuestos con actividad antibacteriana. Para ello debe implementarse el cultivo y masificación de las microalgas Anabaena sp., Oscillatoria sp., Stichococcus sp. y Chlorella sp., así como la evaluación de la actividad antimicrobiana de los extractos obtenidos, en el Laboratorio de Química Sostenible de la Facultad de Ciencias Químicas de la Universidad Central del Ecuador. La implementación y desarrollo de estas metodologías permitirá el desarrollo de futuras investigaciones y la consolidación de líneas de investigación. Es así que el siguiente paso consiste en aislar los componentes con probable actividad antibacteriana mediante técnicas cromatográficas y con ellos evaluar cuantitativamente la actividad antimicrobiana.

\section{Parte experimental}

\subsection{Cultivo y masificación de microalgas}

Los medios de cultivo usados fueron BG1 1 para las microalgas Stichococcus sp. y Oscillatoria sp., BG 110 para Anabaena sp., que se diferencia del anterior por su stock 1 que carece de nitrógeno y finalmente $M 1$ para Chlorella sp., los cuales fueron preparados y puede encontrarse su composición en la literatura. [8]

El cultivo de las microalgas se realizó a partir de muestras preservadas en ceparios del Laboratorio de Química Sostenible, las mismas que se sembraron mediante estriación en cajas Petri con cada uno de los medios específicos para cada género de microalga, tal como se mencionó anteriormente y se colocaron bajo una fuente de luz con fotoperíodos de 24 horas luz. A partir de estos cultivos se da un pase a medio líquido de modo que se permita el desarrollo y la masificación de las microalgas, transfiriendo el cultivo cada 10 a 12 días a un frasco de mayor capacidad de volumen. Sin embargo, en cultivos líquidos se manejó un fotoperíodo de 12 horas luz y 12 horas oscuridad, además de adaptar una fuente de aireación mediante bombas de pecera. [9] La temperatura de los cultivos fue aproximadamente $20^{\circ} \mathrm{C}$, debido a que los géneros de microalgas usados en este estudio, tras 
procesos de adaptación lograron desarrollarse adecuadamente a temperatura ambiente.

La biomasa de microalgas se obtuvo mediante la separación del medio de cultivo de la biomasa algal mediante sedimentación de forma natural y de acuerdo al género de microalga en ocasiones con ayuda de centrifugación a bajas revoluciones por minuto (2000 - $2500 \mathrm{rpm}$ ) mediante una centrifugadora marca Thermo Fisher Scientific. El género Chlorella sp. con respecto al resto de microalgas usadas, corresponde a una estructura celular bastante pequeña al no presentar morfología filamentosa, por lo cual se generó retardo en el proceso de sedimentación optando así por el uso de centrifugación. Siguiendo este proceso se realizaron varios lavados con agua destilada asegurando la eliminación completa del medio de cultivo e inmediatamente se llevó a cabo el proceso de deshidratación mediante incubación a $40^{\circ} \mathrm{C}$ en una incubadora bacteriológica durante 24 horas aproximadamente. Finalmente, se trituró la biomasa deshidratada en un mortero de porcelana con el fin de obtener un polvo homogéneo, el mismo que se almacenó en tubos de plástico tras pesar la masa obtenida. Se cubrieron los tubos con papel aluminio y se los almacenó en un refrigerador a una temperatura de $4^{\circ} \mathrm{C}$ hasta su uso [9].

\subsection{Extracción Soxhlet de microalgas}

Para este proceso se pesa la biomasa algal en una cantidad aproximada de 3 a 4 gramos y se la envuelve en un capuchón de papel filtro, a la par se arma el equipo Soxhlet, tal como se indica en la literatura [10] y se inicia el proceso de extracción repitiéndolo durante aproximadamente 24 horas, obteniendo así extractos con tres solventes de diferente polaridad: etanol $80 \%$, metanol $99,9 \%$ y hexano $99,9 \%$. Inmediatamente se recupera el extracto concentrado mediante el rotavapor marca IKA HB 10 [10]. Finalmente, el extracto obtenido se guarda en frascos de vidrio ámbar de modo que se evite cualquier reacción con la luz y se lo almacena a $4^{\circ} \mathrm{C}$.

\subsection{Evaluación de la actividad antibacteria- na de los extractos de microalgas}

La actividad antibacteriana de los extractos obtenidos fue evaluada mediante la técnica de dilución en agar, con la cual se identificó a los extractos que presentan actividad frente a Staphylococcus aureus ATCC 25923 y Escherichia coli ATCC 25922. Luego se aplicó el método de Kirby Baver, solamente con aquellos extractos en los que se evidenció actividad antibacteriana, de modo que se obtuvo halos de inhibición que fueron comparados con antibióticos de amplio espec- tro de uso convencional como ciprofloxacina $5 \mu \mathrm{g}$ y trimetoprima/sulfametoxazol $25 \mathrm{\mu g}$.

En primer lugar se desarrolló el método de dilución en agar para el cual se preparó el medio Mueller Hinton agar marca DIFCO, el mismo que se usa en ambos ensayos de sensibilidad. Una vez fundido tras la esterilización en autoclave marca Lab Tech modelo LAC - 5065SP, se le incorpora cada uno de los extractos de microalgas concentrados en una proporción de 9:1 [1 1] y se procede a homogenizar totalmente esta mezcla para distribuir en cajas Petri a una temperatura de $45^{\circ} \mathrm{C}$ aproximadamente. Se prepararon inóculos de la cepa Escherichia coli ATCC 25922 y de Staphylococcus aureus ATCC 25923, a una escala de turbidez 0,5 McFarland (equivalente a 1,5 × $10^{8} \mathrm{UFC} / \mathrm{mL}$ ) ajustada mediante método espectrofotométrico. Con los inóculos se obtuvieron diluciones de diferentes concentraciones, desde $1 \times 10^{7}$ hasta llegar a $1 \times 10^{4}$ células $/ \mathrm{mL}$. Un volumen de $2 \mu l$ de cada dilución fue depositado en la superficie del agar. Las placas Petri se incubaron de 16 a 20 horas a $37^{\circ} \mathrm{C}$ para evidenciar la inhibición o no de los microorganismos ante la presencia de los componentes bioactivos de las microalgas [1 1]. Se usó como control positivo de crecimiento, el desarrollo de las dos cepas ATCC en agar Mueller Hinton sin adicionar ningún extracto ni solvente, pudiendo observar el crecimiento de cada una de las cepas en sus distintas concentraciones desde $10^{7}$ hasta $10^{4} \mathrm{UFC} / \mathrm{mL}$; mientras que como controles negativos se usaron cada uno de los solventes usados en la extracción, los que se adicionaron en una proporción 9:1 al igual que los extractos (ver figura 1). [11]. Además en aquellos extractos que presentaron actividad antibacteriana al estar concentrados, se determinó la última dilución hasta la que el extracto genera la sensibilidad (MIC).

Una vez obtenidos los resultados en la técnica anterior se aplica el método de Kirby Baver, para lo cual se preparó el agar Mueller Hinton. Paralelamente se preparan los discos de papel filtro (Whatman \# 42), de 6 $\mathrm{mm}$ de diámetro, en los que se colocó uniformemente cada uno de los extractos en un volumen de $20 \mu \mathrm{L}$, haciendo uso de micropipetas. Las cepas ATCC a utilizarse son cultivos de 24 horas. Una vez listos todos los materiales se ajustó el inóculo de cada cepa a una turbidez 0,5 McFarland [1 1], con el que se realizó el hisopado por toda la placa de agar y finalmente se colocó sobre el agar hisopado los discos impregnados con el extracto y se espera de 10 a 15 minutos para que se adhieran totalmente. Tras una incubación de 18 a 24 horas, de existir actividad antibacteriana por parte de los extractos, se observan halos de inhibición alrededor de los discos, en los cuales se midió su diámetro en milímetros [11] [12]. 
Se usaron como controles negativos a discos de papel filtro sin ningún aditivo y discos impregnados con los solventes: hexano 99,9\%; etanol $80 \%$ y metanol $99,9 \%$, mientras que como controles positivos se usaron a dos antibióticos de amplio espectro: trimetopri$\mathrm{ma} / \mathrm{sulfametoxazol} \mathrm{de} 25 \mu \mathrm{g}$ y ciprofloxacina de $5 \mu \mathrm{g}$.

\subsection{Tamizaje fitoquímico}

Este análisis fitoquímico se basó en pruebas preliminares para la identificación cualitativa de compuestos químicos en los extractos que presentaron actividad antibacteriana, tal como alcaloides, fenoles, taninos, flavonoides, antraquinonas, terpenoides, saponinas y azúcares reductores.

La identificación de alcaloides se la desarrolló mediante reacción de Mayer y Wagner; fenoles totales y taninos mediante reacción con cloruro férrico; flavonoides con la denominada prueba con $\mathrm{H}_{2} \mathrm{SO}_{4}$, antraquinonas con prueba de Borntrager; terpenoides con prueba de Liebermann- Burchard y prueba de Salkowski; saponinas mediante ensayo de la espuma y azúcares reductores mediante reacción de Fehling. [13] [14]

\subsection{Análisis estadístico}

Los halos de inhibición obtenidos mediante la técnica de Kirby Baver fueron sometidos a un análisis de varianza de dos factores (ANOVA), donde el factor a es el tipo de extracto y el factor $b$ es la dilución del extracto, cada uno con sus respectivos niveles. Luego se aplica un análisis de Tukey para establecer la presencia de diferencia estadísticamente significativa entre todas las medias comparadas. Finalmente, se aplicó análisis $t$ de Student para comparar los tamaños de los halos de inhibición de los extractos concentrados respecto a los controles positivos: ciprofloxacina 5 $\mu \mathrm{g}(\mathrm{CIP})$ y trimetoprima/ sulfametoxazol $25 \mu \mathrm{g}$ (SXT).
Todo el análisis fue realizado con un nivel de confianza del 95\%, en el programa estadístico GraphPad PRISM® Ver. 6.01.

\section{Resultados y Discusión}

\subsection{Evaluación de la actividad antibacte- riana de los extractos de microalgas}

En primer lugar se detallan los resultados obtenidos mediante la técnica de dilución en agar. Esta metodología permite determinar la sensibilidad o resistencia de un microorganismo frente a distintos antibióticos y a varias concentraciones del mismo, por tanto esta técnica permitió determinar que 2 de los 12 extractos presentaron actividad antibacteriana y ambos fueron extractos metanólicos de las microalgas Oscillatoria sp. y Stichococcus sp. Ambos extractos presentaron actividad frente a la cepa Staphylococcus aureus ATCC 25923, mientras que ningún extracto generó actividad frente a Escherichia coli ATCC 25922. Es posible que la complejidad de la pared celular (delgada capa de peptidoglucano y cantidades considerables de ácidos teicoico y teicurónico) [15] que presentan las bacterias Gram negativas proteja a las células del acceso de los componentes presentes en el extracto. Sin embargo, se debería ampliar el estudio a un mayor número de especies Gram positivas y Gram negativas para poder profundizar en esta hipótesis.

El ensayo con los controles negativos (solventes) permitió evidenciar que los solventes no son los responsables de la inhibición generada, pudiendo así asociar dicha actividad a los componentes bioactivos extraídos. El desarrollo de las dos cepas ATCC en agar Mueller Hinton, se usó como control positivo de crecimiento donde se observó el crecimiento de cada una de las cepas en sus distintas concentraciones desde $10^{7}$ hasta $10^{4} \mathrm{UFC} / \mathrm{mL}$ (ver figura 1). [11]

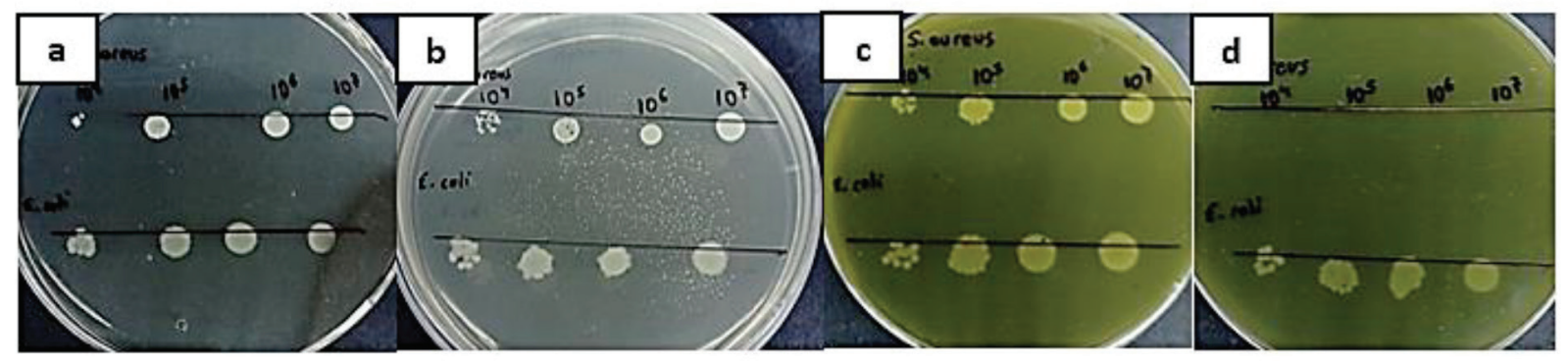

Figura 1. Técnica de dilución en agar. Porción superior de la placa Staphylococcus aureus e inferior Escherichia coli a) control positivo: desarrollo en agar Mueller Hinton, b) control negativo: adición de solvente al medio, c) extracto no genera inhibición y d) extracto genera inhibición. 
En aquellos extractos que presentaron actividad antibacteriana al estar concentrados frente la cepa Staphylococcus aureus, se determinó la última dilución hasta la que el extracto genera la actividad
(CMI), resultados que se muestran en la tabla 1 y 2 para el extracto metanólico de Oscillatoria sp. (MO) y extracto metanólico de Stichococcus sp. (MS), respectivamente.

Tabla 1. Resultados de extracto metanólico de Oscillatoria sp. frente a S. aureus ATCC 25923

\begin{tabular}{ccccc}
\hline \multirow{2}{*}{ Mo } & \multicolumn{5}{c}{ Respuesta de S. aureus } \\
\cline { 2 - 5 } & $\mathbf{1 0 ^ { 4 }}$ & $\mathbf{1 0 ^ { 5 }}$ & $\mathbf{1 0 ^ { 6 }}$ & $\mathbf{1 0 ^ { 7 }}$ (UFC/mL) \\
\hline Extracto concentrado & + & + & + & + \\
\hline Dilución 1:2 & + & + & + & + \\
\hline Dilución 1:4 & + & + & + & + \\
\hline Dilución 1:8 & + & + & + & + \\
\hline Dilución 1:16 & + & + & + & + \\
\hline Dilución 1:32 & + & + & + & +
\end{tabular}

MO: extracto metanólico de Oscillatoria sp. Resultados: (+) inhibición y (-) no inhibición

Tabla 2. Resultados de extracto metanólico de Stichococcus sp. frente a S. aureus ATCC 25923

\begin{tabular}{ccccc}
\hline \multirow{2}{*}{ MS } & \multicolumn{5}{c}{ Respuesta de S. aureus } \\
\cline { 2 - 5 } & $\mathbf{1 0 ^ { 4 }}$ & $\mathbf{1 0 ^ { 5 }}$ & $\mathbf{1 0}^{\mathbf{6}}$ & $\mathbf{1 0}^{\mathbf{7}}$ (UFC/mL) \\
\hline Extracto concentrado & + & + & + & + \\
\hline Dilución 1:2 & + & + & + & + \\
\hline Dilución 1:4 & + & + & + & + \\
\hline Dilución 1:8 & + & + & + & + \\
\hline Dilución 1:16 & + & - & - & - \\
\hline Dilución 1:32 & - & - & - & - \\
\hline Dilución 1:64 & - & + & + & + \\
\hline MS: extracto metanólico de Stichococcus sp.; Resultados: (+) inhibición y (-) no inhibición
\end{tabular}

A partir de los resultados de ambos extractos mediante la técnica de dilución en agar, se observó que la cepa bacteriana Staphylococcus aureus fue más sensible el extracto metanólico de Oscillatoria sp. con respecto al extracto metanólico de Stichococcus sp. El primer extracto inhibe al microorganismo hasta con una dilución $1: 32$, mientras que el segundo solamente logra inhibir hasta con una dilución de 1:16, y a todas las concentraciones del inóculo bacteriano.

Luego se aplicó la técnica de Kirby Baver haciendo uso de aquellos extractos que presentaron actividad antibacteriana, es decir con extracto metanólico de Oscillatoria sp. (MO) y extracto metanólico de Stichococcus sp. (MS). Método que se llevó a cabo con 
el fin de determinar el tamaño del halo de inhibición $(\mathrm{mm})$ por parte de ambos extractos concentrados $(E)$ y realizando diluciones $1: 2$ y $1: 4$ de cada uno de ellos, resultados que se muestran en la tabla 3 .

Tabla 3. Halos de inhibición generados por los extractos metanólicos de Oscillatoria sp. y Stichococcus sp. frente a Staphylococcus aureus ATCC 25923

\begin{tabular}{|c|c|c|c|c|c|c|c|}
\hline \multicolumn{8}{|c|}{ Diámetro del halo de inhibición en mm } \\
\hline \multicolumn{8}{|c|}{ Tipo de extracto } \\
\hline & & \multicolumn{3}{|c|}{ MO } & \multicolumn{3}{|c|}{ MS } \\
\hline & & R1 & R2 & R3 & R1 & $\mathbf{R 2}$ & R3 \\
\hline \multirow[t]{3}{*}{$\begin{array}{c}\text { Dilución de } \\
\text { extracto }\end{array}$} & $\mathbf{E}$ & 17.76 & 17.01 & 17.83 & 14.21 & 13.69 & 14.01 \\
\hline & $1: 2$ & 15.94 & 16.13 & 15.87 & 11.28 & 12.90 & 13.20 \\
\hline & $1: 4$ & 13.12 & 13.36 & 13.65 & 7.76 & 7.64 & 8.01 \\
\hline
\end{tabular}

MO: extracto metanólico de Oscillatoria sp. y MS: extracto metanólico de Stichococcus sp. E: extracto concentrado, 1:2: dilución 1:2 y 1:4: dilución 1:4; R: número de repetición

Los diámetros de zonas de inhibición fueron sometidos a un análisis estadístico ANOVA de dos factores, donde se determinó que tanto el tipo de extracto (MO y MS) como la dilución del extracto $(E, 1: 2,1: 4)$ generan un efecto significativo sobre el tamaño de los halos de inhibición, es así que Staphylococcus aureus resultó más sensible frente al MO. (ver figura 2). Así también mediante un análisis de Tukey se pudo establecer que existe una diferencia estadísticamente significativa entre todas las medias comparadas, a excepción de los tratamientos E-MS vs 1:3-MO y 1:3-MO vs. 1:2$M S$, en los cuales no se encuentra una diferencia significativa entre las medias concluyendo que estas son estadísticamente iguales, lo que fue reportado con un nivel de confianza del $95 \%$, análisis realizado en el programa estadístico GraphPad PRISM®.

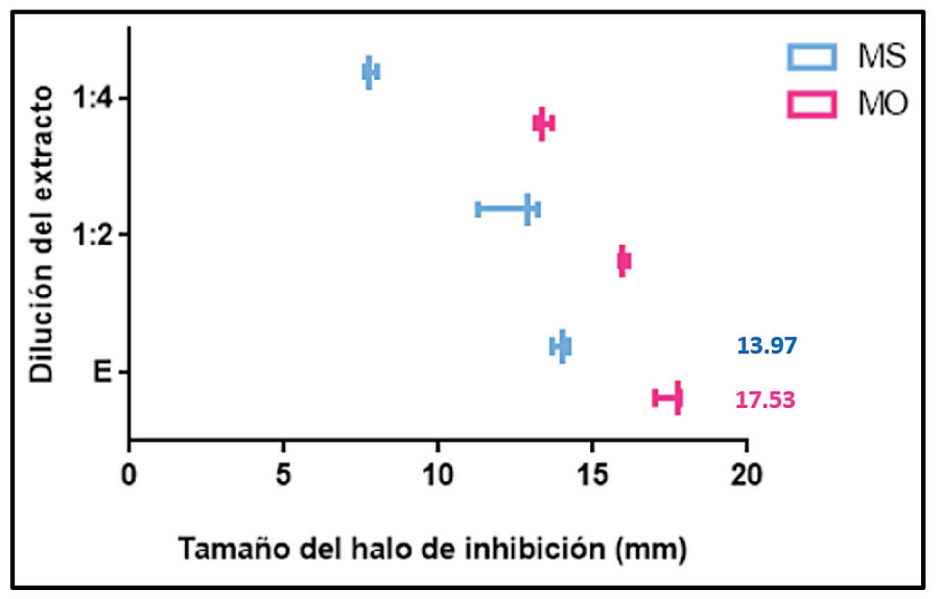

Figura 2. Diagrama de cajas para comparación de medias de halos de inhibición de MO vs. MS, donde se representa el valor mínimo, máximo y la media correspondiente a cada dilución, frente a la cepa Staphylococcus aureus ATCC 25923. MO: extracto metanólico de Oscillatoria sp., MS: extracto metanólico de Stichococcus sp., E: extracto concentrado, dilución 1:2, dilución 1:4 de cada extracto.

Fuente: Programa estadístico GraphPad PRISM® Ver. 6.01 
Con respecto a los controles positivos que fueron los antibióticos de amplio espectro: ciprofloxacina $5 \mu \mathrm{g}(\mathrm{CIP})$ y trimetoprima/ sulfametoxazol $25 \mu \mathrm{g}$ (SXT), se evidenció que los halos obtenidos se encuentran dentro de los rangos que establece el CLSI [16], y así mismo se comprue- ba que no son los solventes ni alguno de los componentes que posee el papel filtro, los agentes que generan la actividad antibacteriana, ya que no hubo halo de inhibición en estos ensayos. En la figura 3 se muestran imágenes del ensayo realizado mediante el método de Kirby Baver.

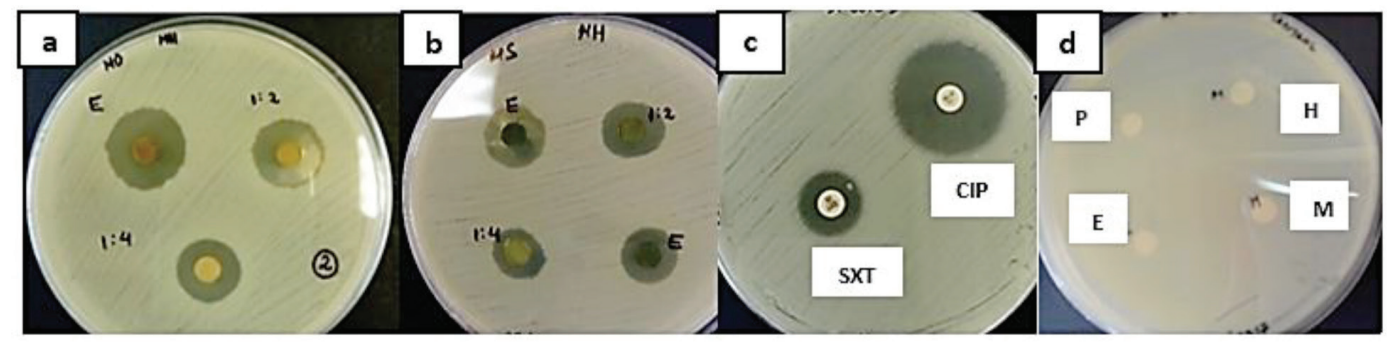

Figura 3. Método de Kirby Baver. Extracto metanólico concentrado, dilución 1:2 y dilución 1:4. a) Oscillatoria sp. b) Stichococcus sp.; c) controles positivos: ciprofloxacina $5 \mu \mathrm{g}(\mathrm{CIP}=30 \mathrm{~mm})$ y trimetoprima/ sulfametoxazol $25 \mu \mathrm{g}(\boldsymbol{S X T}=24 \mathrm{~mm}) \mathrm{d}$ ) controles negativos: $\boldsymbol{P}=$ papel filtro, $\boldsymbol{H}=$ hexano, $\mathbf{E}=$ etanol y $\mathbf{M}=$ metanol

Mediante análisis t de Student se demuestra diferencia significativa en todos los casos al ser comparados los extractos metanólicos de Oscillatoria sp. y Stichococcus sp. con respecto a los controles positivos: ciprofloxacina $5 \mathrm{\mu g}(\mathrm{ClP})$ y trimetoprima/ sulfametoxazol
$25 \mu \mathrm{g}(\mathrm{SXT})$, tomando en cuenta las tres repeticiones realizadas. Así se concluye que estos últimos generan mayor sensibilidad en la cepa bacteriana Staphylococcus aureus con respecto a los extractos. Los resultados del análisis estadístico se muestran en la figura 4.

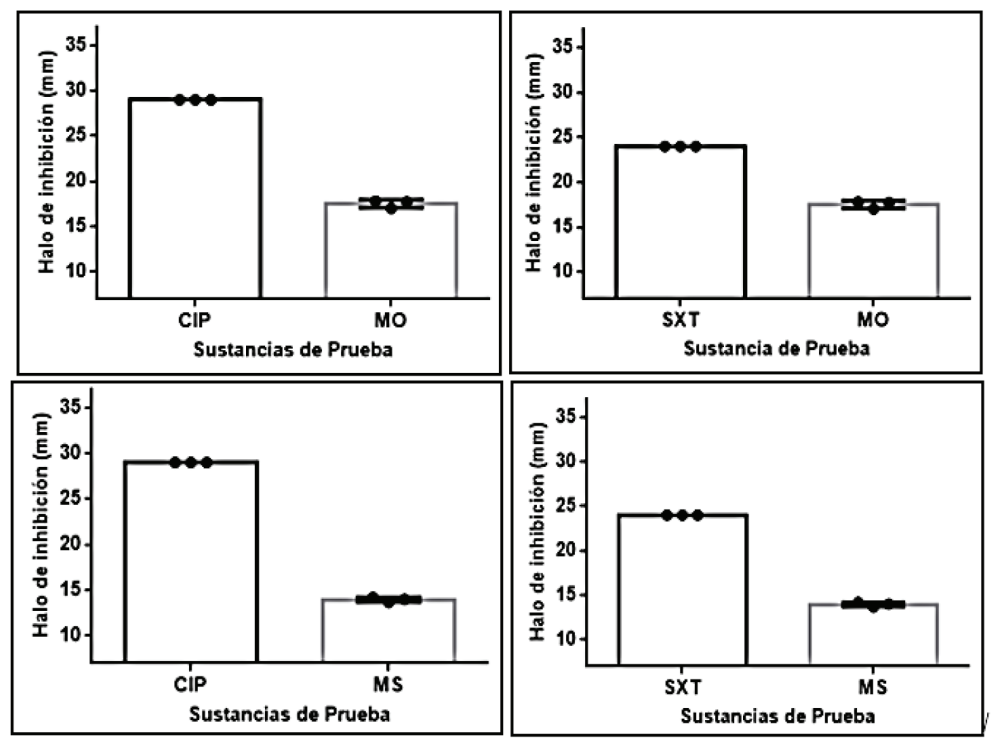

Figura 4. Diagrama de dispersión con barras-comparación de controles positivos (SXT y CIP) contra extractos concentrados (MO y MS) frente a Staphylococcus aureus ATCC 25923. Donde SXT: trimetoprima/sulfametoxazol $25 \mu \mathrm{g}$; CIP: ciprofloxacina 5 jg, MO: extractos metanólicos de Oscillatoria sp. y MS: extractos metanólicos de Stichococcus sp.

Fuente: Programa estadístico GraphPad PRISM® Ver. 6.01

\subsection{Tamizaje fitoquímico}

Este tamizaje fitoquímico se basó en una serie de pruebas cualitativas para distintos grupos químicos, mediante reacciones de precipitación y coloración. Se escogió al azar uno de los extractos que no presentó actividad antibacteriana, este fue el extracto metanólico de Anabaena sp., el mismo que se usó 
como control negativo. Se evidenció que el extracto metanólico de Anabaena sp. no posee alcaloides, flavonoides ni terpenoides a diferencia de los extractos metanólicos de Oscillatoria sp. y Stichococcus sp., resultados que se muestra en la tabla 4 . Se puede inferir que probablemente alguno de estos compuestos químicos sea el responsable de la actividad antibacteriana, sin embargo, debe tenerse en cuenta que este tamizaje solamente brinda datos preliminares sobre los componentes que conforman los extractos, por lo que deberá confirmarse con análisis cuantitativos.

Tabla 4. Resultados de tamizaje fitoquímico en tres extractos metanólicos de microalgas

\begin{tabular}{|c|c|c|c|c|c|}
\hline \multirow{2}{*}{$\begin{array}{l}\text { Compuesto } \\
\text { Químico }\end{array}$} & \multirow{2}{*}{ Reacción } & \multicolumn{3}{|c|}{ Extractos } & \multirow{2}{*}{ Interpretación positiva } \\
\hline & & MO & MS & MA & \\
\hline \multirow[b]{2}{*}{ Alcaloides } & Reacción de Wagner & + & + & - & Precipitación café rojiza \\
\hline & Reacción de Mayer & + & + & - & $\begin{array}{l}\text { Precipitado o coloración amarilla } \\
\text { cremosa }\end{array}$ \\
\hline Flavonoides & Prueba con $\mathrm{H}_{2} \mathrm{SO}_{4}$ & + & + & - & Coloración naranja \\
\hline \multirow{2}{*}{$\begin{array}{l}\text { Terpenoides/ } \\
\text { Esteroides }\end{array}$} & $\begin{array}{c}\text { Reacción de Liebermann - } \\
\text { Burchard }\end{array}$ & + & + & - & Aro de esteroide color café \\
\hline & Reacción de Salkowski & + & + & - & $\begin{array}{c}\text { Coloración café rojiza en la cara } \\
\text { interior }\end{array}$ \\
\hline Antroquinonas & Reacción de Borntrager & - & - & - & Coloración rosada \\
\hline Fenoles & Prueba con $\mathrm{FeCl}_{3}$ & + & + & + & Color negro azulado \\
\hline Taninos & Prueba de $\mathrm{FeCl}_{3}$ & - & - & - & Color verde oscuro \\
\hline Saponinas & Prueba de espuma & - & - & - & $\begin{array}{c}\text { Burbujas de espuma persisten al } \\
\text { someter a calentamiento y tiene una } \\
\text { altura mayor a } 5 \mathrm{~cm} \text {. }\end{array}$ \\
\hline $\begin{array}{l}\text { Carbohidratos } \\
\text { (Azúcares } \\
\text { reductores) }\end{array}$ & Reacción de Fehling & - & - & - & Precipitado de coloración rojiza. \\
\hline
\end{tabular}

MS: extracto metanólico de Stichococcus sp., MO: extracto metanólico de Oscillatoria sp., MA: extracto metanólico de Anabaena

En base a análisis fitoquímicos previos se han descrito componentes con importancia antibacterial como son los flavonoides, alcaloides, esteroides y saponinas [13] [14], compuestos bioactivos que también se encontraron en los extractos de estudio, a excepción de las saponinas que no fueron identificadas, por lo que se podría inferir que alguno de estos compuestos pueden ser los responsables de la actividad antibacteriana, en concordancia con los estudios ya publicados. Para confirmarlo, se requiere estudios adicionales que permitan aislar 0 sintetizar los potenciales principios activos y evaluar cuantitativamente su actividad antimicrobiana (MIC concentración mínima inhibitoria, NIC concentración no inhibitoria, e IC50 concentración inhibitoria del $50 \%$ de la población).

\section{Conclusiones}

La técnica de dilución en agar permitió identificar que a partir de 12 extractos, 4 etanólicos, 4 metanólicos y 4 hexánicos, fueron solamente los extractos metanólicos de Oscillatoria sp. y Stichococcus sp. los que presentaron actividad antibacteriana y lograron inhibir a la cepa bacteriana Staphylococcus aureus ATCC 25923, mientras que la cepa de Escherichia coli ATCC 25922 no fue inhibida por ningún extracto, además de ello se evidencia una mayor sensibilidad de Staphylococcus aureus frente al extracto de Oscillatoria sp., demostrada tanto en la técnica de dilución en agar como por el método de difusión en disco y estadísticamente. Además se nota que el tamaño de los halos de inhibición son dependientes de la dilución del extracto.

Se demostró diferencia significativa entre los halos de inhibición generados por los extractos con respecto a antibióticos de amplio espectro de uso convencional, concluyendo que estos antibióticos generan mayor sensibilidad que los extractos de las microalgas. En el tamizaje fitoquímico se identificaron los siguientes compuestos bioactivos: fenoles como los flavonoides, 
terpenoides, esteroides y alcaloides, los mismos que están presentes tanto en el extracto de la microalga Oscillatoria sp. como Stichococcus sp., por lo que se cree que alguno de ellos o en conjunto podrían ser los responsables de la actividad antibacteriana generada, ya que en estudios similares realizados previamente por Kavitha et al. y Rajendran et al. se identificaron los mismos componentes en extractos de diversas microalgas, donde usaron varios solventes. [13] [14]

Se encontraron discrepancias con respecto a estudios similiares, enfocadas específicamente a la actividad antibacteriana, es así el caso de un estudio mencionado en la sección 1, el cual fue publicado en el año 2014 por Campoverde y Pomaquiza, quienes usaron extractos metanólicos de Oscillatoria sp., al igual que en el presente estudio. [6] A pesar de ello, no evidenciaron inhibición de ninguno de los microorganismos ensayados, lo cual puede asociarse al origen de las microalgas usadas, pudiendo inferir que las microalgas antárticas del presente estudio tienen ventaja sobre las otras. Al ser microalgas psicrófilas, presentan una alta capacidad de adaptación, por lo cual son capaces de desarrollar mecanismos que les permiten sobrevivir a condiciones extremas y por todo ello son atractivas para una gran cantidad de aplicaciones biotecnológicas. [17]

El siguiente paso en esta investigación consistirá en aislar los componentes con probable actividad antibacteriana mediante técnicas cromatográficas y con ellos evaluar cuantitativamente la actividad antimicrobiana, de modo que se pueda determinar MIC, NIC e IC50.

\section{Agradecimientos}

Al Instituto Antártico Ecuatoriano, por facilitar la investigación con micro algas antárticas recogidas en la estación Predro Vicente maldonado.

Bibliografía

[1] Malbrán, C. G. (2015). Resistencia a los antimicrobianos: causas, consecuencias y perspectivas en Argentina. Argentina: Dpto. Bacteriología del Instituto Nacional de Enfermedades Infecciosas (INEI). Recuperado de: http://186.33.221.24/medicamentos//files/Resistencia_antimicrobiana_en_Argentina.pdf

[2] OMS. (2016). Resistencia a los antimicrobianos. Recuperado el 18 de Marzo de 2017, de http://www.who.int/mediacentre/factsheets/ fs194/es/

[3] Amaro, H. M., Guedes, A. C., \& Malcata, F. X. (2011). Antimicrobial activities of microalgae : an invited review. Science against Microbial Pathogens: Communicating Current Research and Technological Advances, 2(3), 1272-1280.

[4] Rosales-Loaiza, N., Hassanhi, M., \& Morales, E. (2012). Actividad Biológica de extractos de dos cepas de la Cianobacteria NOSTOC. Centro de Investigaciones Biológicas, 46(1), 45-62

[5] Pérez, M. J., Falqué, E., \& Domínguez, H. (2016). Antimicrobial Action of Compounds from Marine Seaweed. Revista Marine Drugs, 14(52), 1-38

[6] Campoverde-Alvarado, M. V., \& Pomaquiza-Lema, G. V. (2014). Determinación de la Actividad Antibacteriana de Euglena viridis y OsciIlatoria sp. sobre Staphylococcus aureus y Escherichia coli. Universidad de Cuenca. 
[7] Barona-Altamirano, A. C. (2014). Determinación del Potencial Antimicrobiano de la Microalga Chlorella extraída de las aguas empozadas de las acequias de Atocha, Titulum y El Socavón del Cantón Ambato. Universidad Técnica de Ambato.

[8] Barsanti, L., \& Gualtieri, P. (2006). Algae: Anatomy, Biochemistry and Biotechnology. Boca Ratón, USA: Taylor \& Francis Group.

[9] MALGAS. (2013). Aplicaciones de las microalgas: estado de la técnica (1 ed.). Asturias: AST Ingeniería S.L.

[10] Núñez, C. E. (2008). Extracciones con Equipo Soxhlet. Recuperado el 19 de Septiembre de 2016, de cenunez.com.ar.

[11] CLSI. (2012). Methods for Dilution Antimicrobial Susceptibility Tests for Bacteria That Grow Aerobically; Approved Standard-Ninth Edition (9 ed., Vol. 32). Wayne, PA: Clinical and Laboratory Standards Institute.

[12] Desbois, A. P., \& Smith, V. J. (2015). Chapter 25: Disk Diffusion Assay to Assess the Antimicrobial Activity of Marine Algal Extracts. In Natural Products From Marine Algae: Methods and Protocols, Methods in Molecular Biology (Vol. 1308, pp. 403-410). Obtenido de: http:// doi.org/10.1007/978-1-4939-2684-8

[13] Rajendran, N., Karpanai Selvan, B., Sobana Piriya, P., Logeswari, V., Kathiresan, E., Tamilselvi, A., \& John Vennison, S. (2014). Phytochemicals, antimicrobial and antioxidant screening from five different marine microalgae. Journal of Chemical and Pharmaceutical Sciences, 7(2), 78-85. Obtenido de: http://jchps.com/specialissues/Special issue2/jchps si2 13 Nishanthi rajencdran das 78-85.pdf

[14] Kavitha, J., \& Palani, S. (2016). Phytochemical screening, GC-MS analysis and antioxidant activity of marine algae Chlorococcum humicola. World Journal of Pharmacy and Pharmaceutical Sciences, 5(6), 1154-1167. Obtenido de: http://doi.org/10.20959/wjpps20166-6871

[15] Morse, S. A., \& Carroll, K. C. (2010). Microbiología médica. México: McGrawHill.

[16] CLSI. (2017). M100 Performance Standards for Antimicrobial Susceptibility Testing. (27 ed.). USA: 1-282

[17] Lyon, B. \& Mock, T. (2014). Polar Microalgae: New Approaches towards Understanding Adaptations to an Extreme and Changing Environment. Biology, 3(1), 56-80. 